\title{
3D Printing Carbonaceous Objects from Polyimide Pyrolysis
}

Clay B. Arrington ${ }^{1}$, Daniel E. Rau ${ }^{2}$, Johanna A. Vandenbrande ${ }^{3}$, Maruti Hegde ${ }^{4}$, Christopher B. Williams ${ }^{2}$ and Timothy E. Long ${ }^{3 *}$

${ }^{1}$ Virginia Tech, Department of Chemistry and Macromolecules Innovation Institute (MII), Blacksburg, Virginia, USA, 24061

${ }^{2}$ Virginia Tech, Department of Mechanical Engineering and Macromolecules Innovation Institute (MII), Blacksburg, Virginia, USA, 24061

${ }^{3}$ Arizona State University, Biodesign Center for Sustainable Macromolecular Materials and Manufacturing, Tempe, AZ 85281

${ }^{4}$ University of North Carolina at Chapel Hill, Applied Physical Sciences, Chapel Hill, North Carolina, USA, 27599

*To whom correspondence should be addressed. Email: telong@asu.edu. TEL: (480) 965-9539

\section{Supporting information:}

\section{Experimental}

Materials: 4,4'-Oxydianiline (ODA), pyromellitic dianhydride (PMDA), 2-(dimethylamino)ethyl methacrylate (DMAEMA) and diphenyl(2,4,6-trimethylbenzoyl)phosphine oxide (TPO) were purchased from Sigma Aldrich. 4,4'-oxydianiline and pyromellitic dianhydride were sublimed immediately prior to use. TPO and DMAEMA were used as received. Anhydrous N-methyl-2pyrrolidone (NMP, Acros Organics) was stored over molecular sieves. Nitrogen gas (99.999\%) was purchased from Praxair.

Poly(amic acid) (PAA) of PMDA-ODA. PAA with targeted number-average molecular weight $\left(M_{n}\right)$ of $50 \mathrm{k} \mathrm{g} \cdot \mathrm{mol}^{-1}$ was prepared. A $500-\mathrm{mL}$ three-necked, round-bottomed flask was equipped with a mechanical stirrer, a rubber septum, and a nitrogen inlet. Under nitrogen atmosphere, 250 $\mathrm{mL}$ anhydrous NMP and $40.048 \mathrm{~g}$ ODA $(0.200 \mathrm{~mol})$ were added to the flask. After the ODA was dissolved completely, $43.9905 \mathrm{~g}$ PMDA (0.20168 mol) was added to the flask with an additional $70 \mathrm{~mL}$ anhydrous NMP to ensure addition of all PMDA. After stirring for $6 \mathrm{~h}$, another $30 \mathrm{~mL}$ NMP 
(anhydrous) was added to the solution. The mixture was stirred for additional $6 \mathrm{~h}$ at $23{ }^{\circ} \mathrm{C}$ under nitrogen atmosphere. Finally, the solution was flushed with nitrogen and stored in a fridge at -20 ${ }^{\circ} \mathrm{C}$.

PAA DMAEMA pendant salt solution. $150 \mathrm{~g}$ of the PAA solution (dissolved in NMP, 18.9 wt.\% PAA solids) was transferred to a $250-\mathrm{mL}$ three-necked, round-bottomed flask, equipped with a mechanical stirrer and a nitrogen inlet. 0.5 equiv. DMAEMA $(11.43 \mathrm{~mL})$ and $2.5 \mathrm{wt} . \%$ TPO (975 mg dissolved in $0.9 \mathrm{~mL} \mathrm{NMP)} \mathrm{were} \mathrm{added} \mathrm{to} \mathrm{the} \mathrm{solution} \mathrm{and} \mathrm{the} \mathrm{solution} \mathrm{was} \mathrm{stirred} \mathrm{for} 12 \mathrm{~h}$ under nitrogen atmosphere to yield a homogenous 24 wt.\% PAA DMAEMA salt solution. In order to enable additive manufacturing of the PAA pendant salt solutions with vat photopolymerization and effectively tune solution viscosity for printing, the photo-reactive PAA solution was diluted with NMP to 18.0 wt.\% solids.

Vat photopolymerization. VP processing of the PAA salt solution proceeded as previously reported. ${ }^{1}$ Irradiation with broad-spectrum UV-visible light at $250 \mathrm{~mW} / \mathrm{cm}^{2}$ and measuring the cured film thickness at various exposure times, provided the working curve relationship between cure depth and exposure, ${ }^{2}$ as described in detail by Meenakshisundaram et al. ${ }^{3}$ A dynamic moving mask of UV irradiation, provided by a UV projector scanning across the resin surface, generated specimens with cure layers of $150 \mu \mathrm{m}$ thickness. The parts were printed at a scan speed of 2.6 $\mathrm{mm} / \mathrm{s}$ with UV irradiation of $405 \mathrm{~nm}$ at $11.34 \mathrm{~mW} / \mathrm{cm}^{2}$. A recoating step was performed between layers to ensure uniform layer thickness and homogeneity throughout the build volume. The final printed part was carefully removed from the glass slide and rinsed with NMP.

UV-DIW printing process. UV-DIW proceeded as previously described by Rau et al. ${ }^{4}$ The various 3D geometries were deposited on glass substrates with a deposition speed of $8 \mathrm{~mm} / \mathrm{s}, 0.3$ mm layer height, $0.25 \mathrm{~mm}$ tapered nozzle provided by Nordson EFD, and $620.5 \mathrm{kPa}$ extruder 
pressure on a glass substrate. Following complete deposition of each layer, the PAA ink was exposed to the UV light source at $405 \mathrm{~nm}$ and a measured intensity of $14 \mathrm{~mW} / \mathrm{cm}^{2}$ for a minimum of 5 s. To print self-supporting simple cubic structures (SC-structures), parallel roads were deposited $1.5 \mathrm{~mm}$ apart, alternating their direction by $90^{\circ}$ every two layers.

Post-printing process. The crosslinked organogels were removed from the glass substrate and suspended on a thin copper wire to enable uniform drying under air. After 1-2 days, the 3D objects were placed in a vacuum oven and heated to $60^{\circ} \mathrm{C}$, held for one hour and subsequently heated to $200{ }^{\circ} \mathrm{C}$ with a heating rate of $2{ }^{\circ} \mathrm{C} / \mathrm{min}$, and finally held for $30 \mathrm{~min}$ at $200{ }^{\circ} \mathrm{C}$. After cooling to room temperature (cooling rate of $2{ }^{\circ} \mathrm{C} / \mathrm{min}$ ), the objects were transferred to a glass chamber surrounded with a metal heating bath and gradually heated to $420{ }^{\circ} \mathrm{C}$ under vacuum (heating rate of $2{ }^{\circ} \mathrm{C} / \mathrm{min}$ ), held for $30 \mathrm{~min}$ at $420{ }^{\circ} \mathrm{C}$, and returned to room temperature with a cooling rate of $2{ }^{\circ} \mathrm{C} / \mathrm{min}$.

Carbonization of AM PI structures. Imidized parts were placed on alumina boats in a quartz tube furnace and heated under a flow of nitrogen to $1000{ }^{\circ} \mathrm{C}$ from room temperature using a 2 ${ }^{\circ} \mathrm{C} / \mathrm{min}$ heating ramp. The furnace was held at $1000{ }^{\circ} \mathrm{C}$ for $1 \mathrm{~h}$ before cooling to room temperature at a rate of $5^{\circ} \mathrm{C} / \mathrm{min}$.

Analytical Methods: Photorheology was performed using a TA Instruments DHR-2 rheometer with $20 \mathrm{~mm}$ parallel plate geometry, UV curing accessory, and Omnicure S2000 light source equipped with a broad spectrum bulb and 320-500 nm filter. An oscillation procedure of $0.3 \%$ strain and $4 \mathrm{~Hz}$ at $25^{\circ} \mathrm{C}$ with a $500 \mu \mathrm{m}$ gap was utilized during photorheology. Polymer solutions were subjected to oscillation for $30 \mathrm{~s}$ prior to UV irradiation with an intensity of $250 \mathrm{~mW} / \mathrm{cm}^{2}$ for $150 \mathrm{~s}$. Thermogravimetric analysis (TGA) was performed from $25^{\circ} \mathrm{C}$ to $1000{ }^{\circ} \mathrm{C}$ with a $10{ }^{\circ} \mathrm{C} / \mathrm{min}$ heating rate and $\mathrm{N}_{2}$ purge gas using a TA instruments Q500. Solution viscosities in NMP were 
examined using a TA Instruments DHR-3 rheometer. Flow sweeps were conducted using $40 \mathrm{~mm}$ aluminum parallel plate upper geometry and a Peltier plate lower geometry. Shear sweeps from $0.1 \mathrm{~Hz}$ to $500 \mathrm{~Hz}$ at $25^{\circ} \mathrm{C}$ elucidated the viscosity and shear thinning behavior of the polyimide precursors prior to printing. Scanning electron microscopy using a LEO (Zeiss) 1550 Schottky field-emission microscope afforded surface and cross-sectional images of additive manufactured specimens. The specimens were fractured after immersing in liquid $\mathrm{N}_{2}$ for approximately 2 min. A Horiba XploRA PLUS Raman Microscope enabled gathering of Raman spectra for pyrolyzed printed polyimide precursors. Samples were sanded before analysis to provide polished surfaces. A Metrohm Autolab B.V. impedance analyzer scanning from $10^{5}$ to $0.1 \mathrm{~Hz}$ with a $0.2 \mathrm{~V}$ amplitude at $20 \%$ relative humidity and $23{ }^{\circ} \mathrm{C}$ facilitated determination of resistance values for pyrolyzed printed objects.

The custom-designed ultra-violet assisted direct ink write (UV-DIW) printer consisted of a Nordson EFD Ultimus V precision dispenser mounted, which selectively extruded the precursor, and a Keynote Photonics LC4500-UV Digital Light Processing (DLP) projector, which provided UV-irradiation at $405 \mathrm{~nm}$ with a measured intensity of $14 \mathrm{~mW} / \mathrm{cm}^{2}$ on the build plate. The UV light source and the DIW extruder were mounted adjacent on Zaber A-LST500 linear slides that provided linear motion in the XY-direction. The adjacent mounting of the extruder and light source was used to provide each deposited layer with a controlled amount of UV exposure. A Zaber ALST250 linear slide provided translation in the Z-direction. The printer was controlled via a custom-built LabVIEW software program that sent G-Code commands to the printer that synchronized the stop and start of extrusion with the XYZ movement.

The custom-designed vat photopolymerization printer consisted of a UV light source, conditioning optics, a dynamic mask generator (projector) mounted on a XY linear stages, imaging optics, and 
a container with a stage mounted on a linear actuator. A Blue Wave 75 UV Curing spot lamp (300$500 \mathrm{~nm}$ ) with intensity adjustment from Dymax was chosen as a source of ultraviolet light. The conditioning optics (Edmund Optics) ensured that the entire dynamic mask was illuminated by UV-visible light while the imaging optics focused the patterned light onto the photopolymer surface at a magnification ratio of $1: 1$. The dynamic mask consisted of a DLP 0.55 XGA DMD from Texas Instruments with a $1024 \times 768$ rectangular array of aluminum micro-mirrors. Each square micromirror had a side length of $10.8 \mu \mathrm{m}$ producing an effective full projection area of approximately $11.05 \mathrm{~mm} \times 8.29 \mathrm{~mm}$ at the surface of the resin. The achievable scan speeds were in the range of $0-22 \mathrm{~mm} / \mathrm{s}$. The $200 \mathrm{~mL}$ vat size constrained the $\mathrm{Z}$ direction to a maximum of 50 $\mathrm{mm}$. The build platform was fabricated using thermoplastic filament extrusion and tiled with glass microscope slides (AMScope BS-50P-100S-22). The linear actuators (Zaber A-LST0500A-E01, A-LST0250A-E01) for the X, Y, and Z motion were controlled using custom software developed in LabVIEW. A radiometer (UVP: UVX Radiometer with UVX-36 Sensor) was used to measure the intensity of the light source at $365 \mathrm{~nm}$. The total intensity over the spectral range (300-500 $\mathrm{nm}$ ) was calculated by correlating the measured intensity of the light source at $365 \mathrm{~nm}$ with the spectral distribution provided by the manufacturer. From this calculation, a UV irradiation at 405 $\mathrm{nm}$ at $11.34 \mathrm{~mW} / \mathrm{cm}^{2}$ was determined. A GSL1600-100X High Temperature Tube Furnace equipped with purified nitrogen facilitated pyrolysis of additively manufactured polyimide structures. 

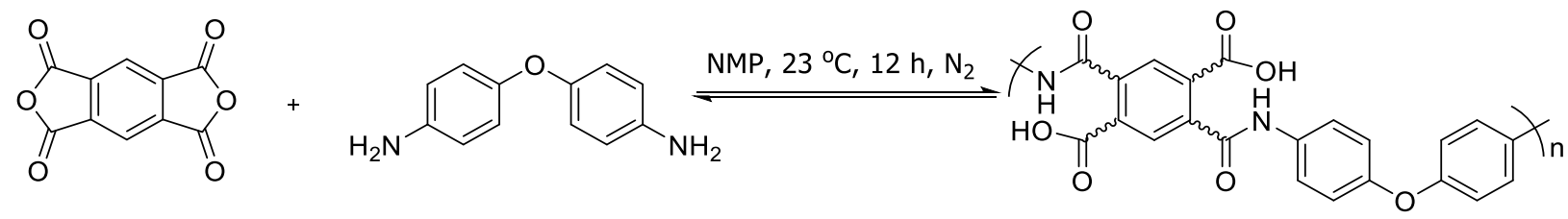

S1. Classical poly(amic acid) formation of PMDA and ODA.

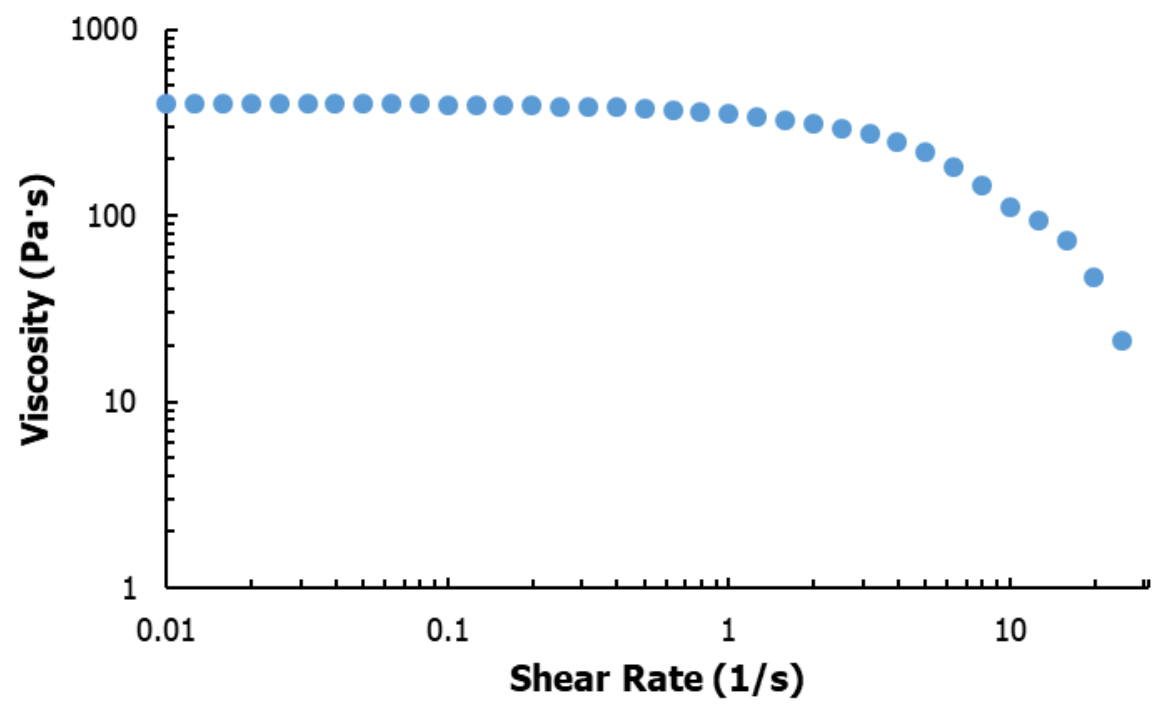

S2. Viscosity (Pa.s) plotted versus shear rate (1/s) for $24 \mathrm{wt} . \%$ 0.5 equiv. PAAs resin in NMP. Solution displays prerequisite shear thinning and viscosity for UV-DIW. 


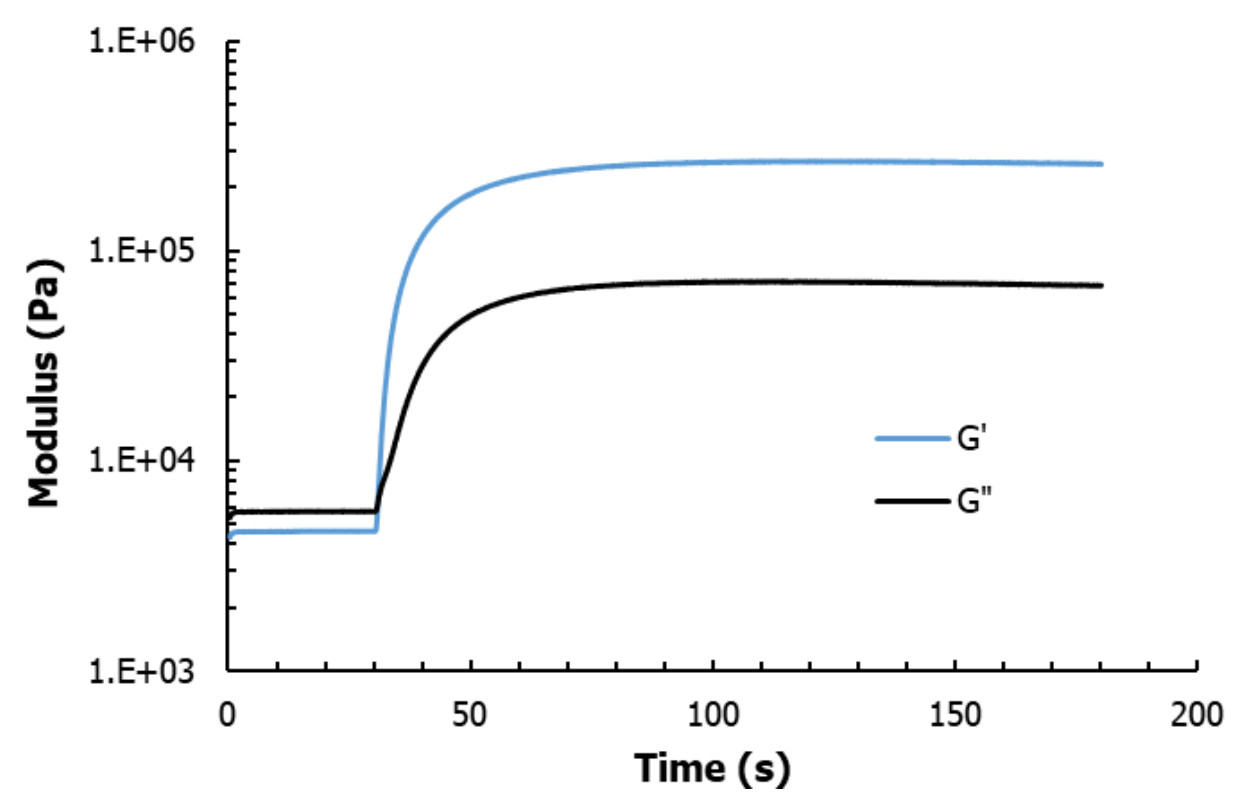

S3. Photorheology of 24 wt.\% 0.5 equiv. PAAs solution in NMP; modulus (Pa) vs time (s) during photopolymerization. Irradiation starts at $30 \mathrm{~s}$. Resins exhibits cross-over times of $\sim 1 \mathrm{~s}$ and high plateau modulus of $>10^{5} \mathrm{~Pa}$.

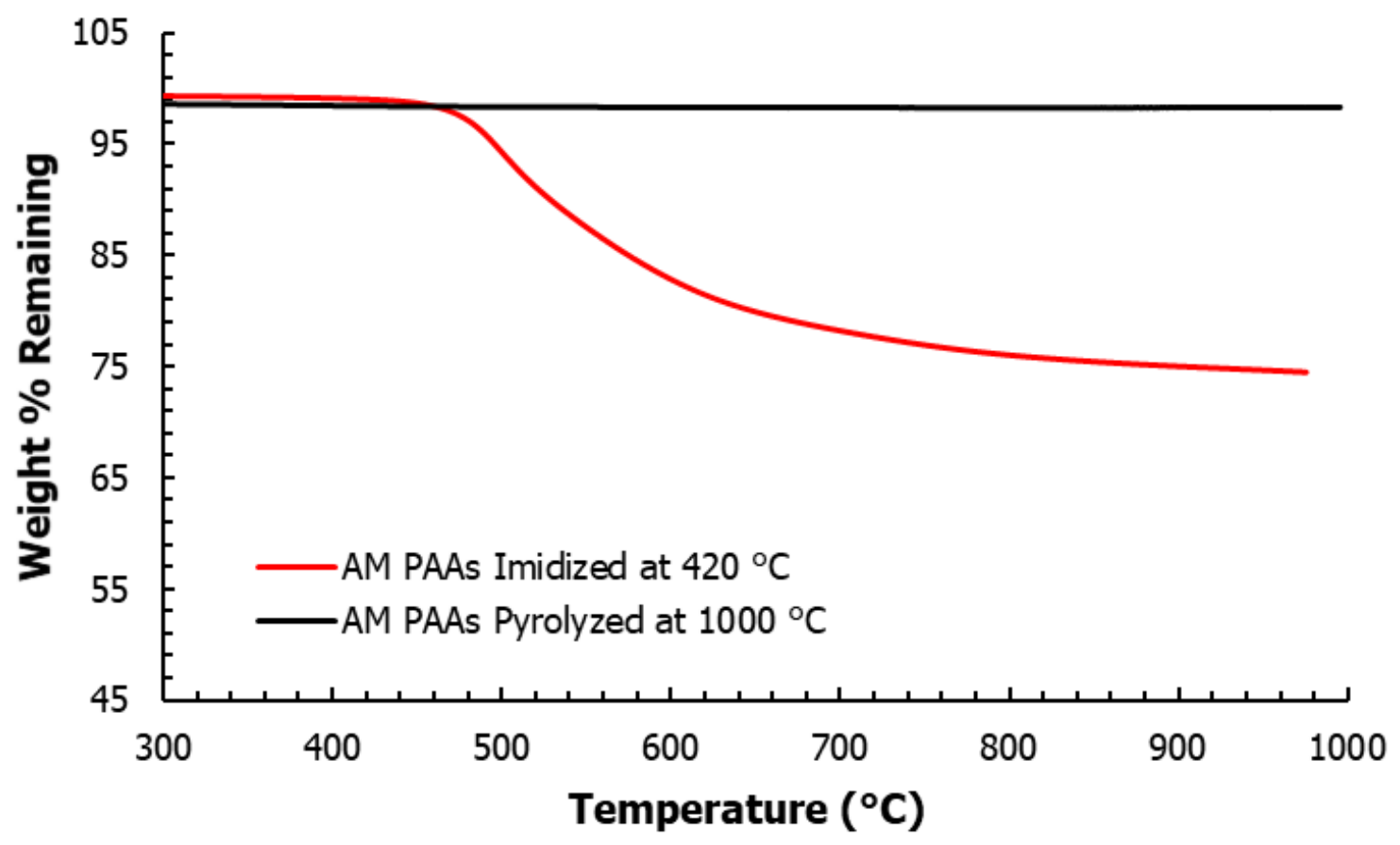

S4. TGA weight loss profiles of imidized PAAS part and PAAS part pyrolyzed at $1000{ }^{\circ} \mathrm{C}$. Imidized sample part previously heated to $420{ }^{\circ} \mathrm{C}$. TGA performed with $10{ }^{\circ} \mathrm{C} / \mathrm{min}$ ramp under nitrogen. Imidized PAAs displays incomplete scaffold removal and $\mathrm{T}_{\mathrm{d}, 5 \%}$ of $505{ }^{\circ} \mathrm{C}$. 


\begin{tabular}{|c|c|}
\hline & Electrical Conductivity $\left(\mathbf{S} \cdot \mathbf{c m}^{-1}\right)$ \\
\hline $\begin{array}{c}\text { Amorphous Carbon from } \\
\text { PMDA-ODA }^{1}\end{array}$ & $6.0 \times 10^{1}$ \\
\hline $\mathbf{1 0 0 0}^{\circ} \mathbf{C}$ & $2.47 \times 10^{0}$ \\
\hline $\mathbf{9 0 0}^{\circ} \mathbf{C}$ & $1.30 \times 10^{0}$ \\
\hline $\mathbf{8 0 0}^{\circ} \mathbf{C}$ & $5.98 \times 10^{-1}$ \\
\hline $\mathbf{7 0 0}^{\circ} \mathbf{C}$ & $1.77 \times 10^{-2}$ \\
\hline
\end{tabular}

S5. Tabulated electrical conductivity values for carbon discs formed from pyrolysis of additively manufactured polyimides at various temperatures as well as amorphous carbon from commercial PMDA-ODA film pyrolyzed at $1000{ }^{\circ} \mathrm{C} .{ }^{5}$

\section{References:}

(1) Herzberger, J.; Meenakshisundaram, V.; Williams, C. B.; Long, T. E. 3D Printing AllAromatic Polyimides Using Stereolithographic 3D Printing of Polyamic Acid Salts. ACS Macro Lett. 2018, 7 (4), 493-497.

(2) Paul, F. J. Rapid Prototyping \& Manufacturing: Fundamentals of Stereolithography Paul Francis Jacobs - Google Books; 1992.

(3) Meenakshisundaram, V.; Sturm, L. D.; Williams, C. B. Modeling A Scanning-Mask Projection Vat Photopolymerization System For Multiscale Additive Manufacturing. $J$. Mater. Process. Technol. 2020, 279, 116546.

(4) Rau, D. A.; Herzberger, J.; Long, T. E.; Williams, C. B. Ultraviolet-Assisted Direct Ink Write to Additively Manufacture All-Aromatic Polyimides. ACS Appl. Mater. Interfaces 2018, 10 (41), 34828-34833.

(5) Inagaki, M.; Ibuki, T.; Takeichi, T. Carbonization Behavior of Polyimide Films with Various Chemical Structures. J. Appl. Polym. Sci. 1992, 44 (3), 521-525. 